\title{
Pyogenic Granuloma
}

\section{Alexander KC Leung ${ }^{1 *}$, Benjamin Barankin ${ }^{2}$ and Kam Lun Hon ${ }^{3}$}

${ }^{1}$ Clinical Professor of Pediatrics, University of Calgary, Pediatric Consultant, Alberta Children's Hospital, Canada

${ }^{2}$ Medical Director and Founder, Toronto Dermatology Centre, Canada

${ }^{3}$ Professor of Pediatrics, Chinese University of Hong Kong, China

\begin{abstract}
Pyogenic granuloma, also known as lobular capillary hemangioma, is a common, acquired, benign vascular proliferation that typically develops as a small erythematous papule on the skin or oral mucosal surface. The papule usually enlarges quickly to a few millimeters over weeks and growth stabilizes over several months. Clinically, pyogenic granuloma presents as a soft dome-shaped papule/nodule or a sessile or pedunculated papule/nodule with a smooth, glistening, erosive, or friable surface. The color is usually bright red to dusky red. Characteristically, the lesion is asymptomatic and painless. Pyogenic granuloma is usually solitary. Cutaneous pyogenic granulomas are commonly located on the head and neck, as well as fingers and toes. In the oral cavity, pyogenic granulomas are more frequent on the gingiva. The lesion tends to bleed and ulcerate even with very minor trauma which brings patients to seek medical care. Although pyogenic granulomas occur in patients of any age, they are more prevalent in children, adolescents, and pregnant women. Cutaneous pyogenic granulomas have no gender predilection whereas the oral mucosal ones have a female to male ratio of 2:1. Trauma and female sex hormones are possible etiologic factors. The diagnosis is usually clinical. Pyogenic granulomas developing during pregnancy tend to resolve on their own after delivery and usually require no treatment. Most other lesions are treated. Surgical excision with linear closure allows histologic examination of the tissue. It also has the lowest rate of recurrence and is therefore the treatment of choice.
\end{abstract}

Keywords: Pyogenic granuloma; Lobulated capillary hemangioma; Friable; Bright red; Surgical excision

\section{Introduction}

Pyogenic granuloma, also known as lobular capillary hemangioma, is a common, acquired, benign vascular proliferation of the skin and mucous membrane [1]. The condition was first described in 1897 who reported four patients with "vascular tumors" on the fingers [2]. The term "pyogenic granuloma" or "granuloma pyogenicum", coined by Hartzell in 1904 [3], is a misnomer as the condition is neither pyogenic nor granulomatous [4]. Although "lobular capillary hemangioma" coined by Meller et al. is a preferred term [5]. The term may confuse it with infantile hemangioma [4].

\section{Epidemiology}

Although pyogenic granulomas occur in patients of any age, they are more prevalent in children, adolescents, and pregnant women [6,7]. Pyogenic granuloma accounts for $0.5 \%$ of all childhood skin nodules $[8,9]$. In the pediatric age group, the mean age of onset is 6.7 years; with $42 \%$ of cases occur by 5 years of age [6]. In the adult population, the incidence peaks in the third decade of life $[6,10]$. Pyogenic granuloma, especially on the gingiva, occurs in approximately 2 to $5 \%$ of pregnancies, usually in the second or third trimester $[11,12]$. In this setting, pyogenic granuloma is often referred to as granuloma gravidarum, granuloma of pregnancy, epulis gravidarum, or pregnancy tumor $[8,12]$. Cutaneous pyogenic granulomas usually have no gender predilection whereas the oral mucosal ones have a female to male ratio of 2:1 [6].

\section{Etiology and Pathogenesis}

The exact etiology is not known. Pyogenic granuloma is considered a reactive vascular response to a variety of stimuli such as trauma and increased levels of female sex hormones. Approximately $7 \%$ of affected patients have a history of trauma preceding the lesion $[8,13]$. Female sex hormones may also play a role as the condition occurs at increased frequency in pregnant women and in those who use oral contraceptive pills $[6,11,14]$. It is believed that trauma and female sex hormones enhance expression of angiogenic factors such as basic fibroblast growth factor (bFGF) and vascular endothelial growth factor (VEGF) which will lead to evolution of the pyogenic granuloma $[6,7,11,15]$. Medications such as isotretinoin, acitretin, cyclosporine, lamivudine, docetaxel, imatinib, and indinavir may also be contributing factors $[8,13,15-18]$. Infections such as caused by herpes simplex type-I and Epstein-Barr virus have also been incriminated [18].

\section{Histopathology}

Histologically, the lesion appears as a lobular proliferation of capillaries with each lobule containing a central feeder vessel surrounded by aggregates of capillaries [13]. The lobules are separated by a fibro-myxoid stroma [6]. In those lesions that are undergoing regression, there may be extensive fibrosis [19].

\section{Clinical Manifestations}

Pyogenic granuloma typically develops as a small erythematous papule on the skin or oral mucosal surface $[4,6]$. The papule usually enlarges quickly to a few millimeters and occasionally a few centimeters over weeks and growth stabilizes over several months $[6,14]$. Clinically, pyogenic granuloma presents as a soft, dome-shaped papule/nodule or a sessile or pedunculated papule/nodule with a smooth, glistening, erosive, or friable surface (Figure 1) $[8,20]$. The color is usually

*Corresponding author: Alexander KC Leung, Clinical Professor of Pediatrics, University of Calgary, Pediatric Consultant, Alberta Children's Hospital, Canada Tel: 403230-3322; E-mail: aleung@ucalgary.ca

Received November 23, 2013; Accepted December 01, 2013; Published January 06, 2014

Citation: Leung AKC, Barankin B, Hon KL (2014) Pyogenic Granuloma. Clinics Mother Child Health 11: e106. doi: 10.4172/2090-7214.1000e106

Copyright: (c) 2014 Leung AKC, et al. This is an open-access article distributed under the terms of the Creative Commons Attribution License, which permits unrestricted use, distribution, and reproduction in any medium, provided the original author and source are credited. 


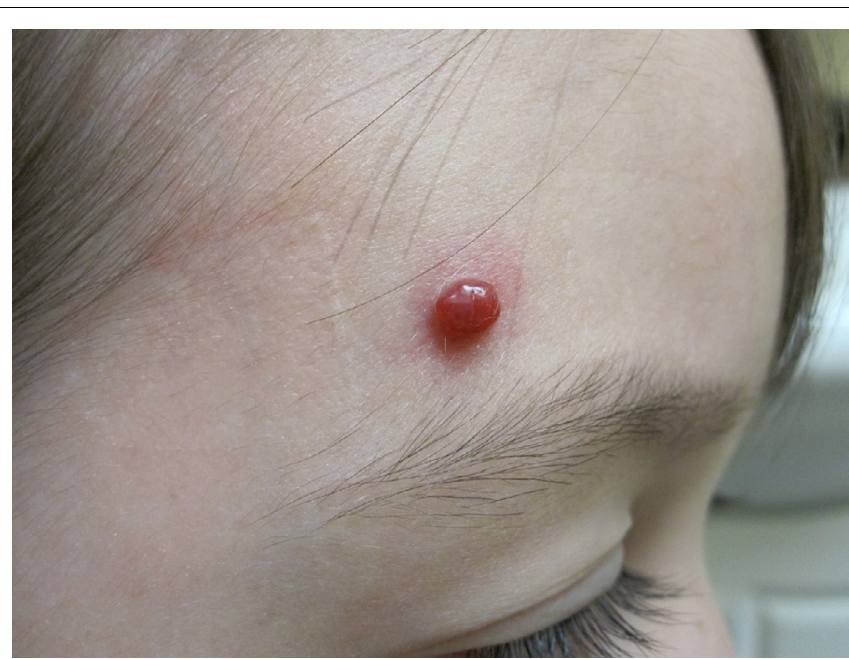

Figure 1: Pyogenic granuloma in the frontal area above the right eyebrow in a 9-year-old girl

bright red to dusky red initially. With time, the vascularity decreases and the lesion tends to become more collagenized and pink [14,20]. Characteristically, the lesion is asymptomatic and painless $[19,20]$. Due to its pronounce d vascularity, pyogenic granuloma tends to bleed and ulcerate even with very minor trauma [6,9]. As such, patients often present with the "band-aid sign" where the lesion is covered by a bandaid before being removed to show the physician. The lesion is usually solitary, but multiple lesions may occur [6,9].

Cutaneous pyogenic granulomas are commonly located on the head and neck (62.5\%), trunk (19.7\%) and extremities (17.9\%), especially the fingers $[6,12]$. In the oral cavity, pyogenic granulomas are more frequent on the gingiva, followed by the lips, tongue, and buccal mucosa $[6,14,20,21]$. Lesions are slightly more common on the maxillary gingiva than the mandibular gingiva, anterior areas than posterior areas, and facial aspect of the gingiva than the lingual or palatal aspect [20]. Nasal pyogenic granulomas generally arise from the nasal septum and/or from turbinates on the roof of the nasal cavity, or in the maxillary sinus [10]. Pyogenic granulomas rarely occur in the gastrointestinal tract, trachea, urinary bladder, and central nervous system $[19,22]$.

Clinical variants such as satellite pyogenic granulomas, subcutaneous pyogenic granulomas, intravenous pyogenic granulomas, and disseminated pyogenic granulomas are rare [13]. Satellite pyogenic granulomas are most commonly seen in adolescents and young adults and commonly seen on the trunk [23]. Satellite lesions tend to occur 4 to 20 weeks after the primary lesion has been excised and to occur in very close proximity to the site of the original primary lesion [23]. Satellitosis might be the result of release of angiogenic factors such as bFGF and VEGF by the primary lesion. Subcutaneous pyogenic granulomas occur predominately in females [24]. The lesion typically presents as a well circumscribed subcutaneous nodule which usually does not bleed or ulcerate [24,25]. Intravenous pyogenic granulomas occur mainly in middle-aged individuals [26]. The lesion is confined within the lumen of a vein $[26,27]$. The lesion typically presents as a soft, subcutaneous, slow-growing nodule which may be bluish, erythematous, or skin-colored $[26,27]$. Sites of predilection include the neck and upper extremities [26]. Disseminated pyogenic granulomas are generally seen after trauma such as burns and in patients with an accompanying systemic or skin disease [28].

\section{Diagnosis}

The diagnosis is mainly clinical. Demoscopy of the lesion reveals red homogenous areas (proliferating vessels) and a white scaly collarette (hyperplastic epithelium) [29]. Dermoscopy increases the diagnostic accuracy and has been shown to be a very useful tool to evaluate pyogenic granuloma [29]. However, dermoscopy is not a substitute for histology, a biopsy is warranted if the diagnosis is in doubt (e.g. to rule out amelanotic melanoma).

\section{Differential Diagnosis}

Pyogenic granuloma has to be differentiated from bacillary angiomatosis (disseminated vascular lesions in immunocompromised individuals) and verruga peruana (crops of vascular nodules in immunocompetent individuals) caused by infection with Bartonella species $[30,31]$. Other differential diagnoses include pedunculated cherry angioma, granulation tissue, infantile hemangioma, venous lake, epulis, glomus, acquired digital fibrokeratoma, amelanotic melanoma, hyperplastic gingival inflammation, peripheral giant cell granuloma, peripheral ossifying fibroma, Spitz nevus, proliferating pilomatricoma, Kaposi's sarcoma, and angiosarcoma [6,8,15,19,32].

\section{Complications}

Pyogenic granuloma can be unsightly and cosmetically disfiguring, especially if it occurs on the face. Other complications include hemorrhage, ulceration, and infection in an ulcerated lesion [8]. Pyogenic granuloma has no malignant potential [31].

\section{Management}

Pyogenic granulomas developing during pregnancy tend to resolve on their own after delivery and usually require no treatment [6]. Most other lesions are treated. A series of treatment modalities are available, including surgical excision, shave excision, laser surgery, electrodessication, curettage, liquid nitrogen cryotherapy, sclerotherapy, topical silver nitrate, and topical imiquimod $[1,6,7,15,33,34]$. Recurrences may occur and are largely attributed to inadequate removal or incomplete destruction of the lesions. Surgical excision with linear closure allows histologic examination of the tissue [4]. It also has the lowest rate of recurrence and is therefore the treatment of choice $[6,9,13,35]$. Surgical excision, however, may leave scars [36].

\section{References}

1. Gencoglan G, Inanir I, Gündüz K (2009) Pyogenic granuloma in two children successfully treated with imiquimod $5 \%$ cream. Pediatr Dermatol 26: 366-368.

2. Poncet A, Dor L (1897) Botyromycose humaine. Rev Chir 18: 996.

3. Hartzell MB (1904) Granuloma pyogenicum. J Cutan Dis Syph 22: 520-525.

4. Leung AK (2011) Pyogenic granuloma. In: Leung AK, ed. Common Problems in Ambulatory Pediatrics: Specific Clinical Problems. Nova Science Publishers, Inc: $143-147$.

5. Mills SE, Cooper PH, Fechner RE (1980) Lobular capillary hemangioma: the underlying lesion of pyogenic granuloma. A study of 73 cases from the oral and nasal mucous membranes. Am J Surg Pathol 4: 470-479.

6. Lin RL, Janniger CK (2004) Pyogenic granuloma. Cutis 74: 229-233.

7. Yang C, Liu S (2013) Treatment of giant pyogenic granuloma with the Nd/YAG holmium laser: a case report. J Cosmet Laser Ther 15: 225-227.

8. Scheinfeld NS (2008) Pyogenic granuloma. Skinmed 7: 89-92.

9. Spinelli C, Di Giacomo M, Bertocchini A, Loggini B, Pingitore R (2009) Multiple 
pyogenic granuloma of the penis in a four-year-old child: a case report. Cases J 2: 7831

10. Patil P, Singla S, Mane R, Jagdeesh KS (2013) Nasal lobular capillary hemangioma. J Clin Imaging Sci 3: 40.

11. Andrikopoulou M, Chatzistamou I, Gkilas H, Vilaras G, Sklavounou A (2013) Assessment of angiogenic markers and female sex hormone receptors in pregnancy tumor of the gingiva. J Oral Maxillofac Surg 71: 1376-1381.

12. Pagliai KA, Cohen BA (2004) Pyogenic granuloma in children. Pediatr Dermatol 21: 10-13.

13. Ting PT, Barankin B (2006) Dermacase Pyogenic granuloma. Can Fam Physician 52: 35-36.

14. Amirchaghmaghi M, Falaki F, Mohtasham N, Mozafari PM (2008) Extragingival pyogenic granuloma: a case report. Cases $\mathrm{J}$ 1:371.

15. Bakan V, Aliagaoglu C, Yildiz A, Emsen M (2008) Multiple pyogenic granulomas on the face after landmine injury. Pediatr Dermatol 25: 397-398.

16. Armstrong K, Weinstein M (2011) Pyogenic granuloma during isotretinoin therapy. J Dermatol Case Rep 26: 5-7.

17. Dika E, Barisani A, Vaccari S, Fanti PA, Ismaili A, et al. (2013) Periungual pyogenic granuloma following imatinib therapy in a patient with chronic myelogenous leukemia. J Drugs Dermatol 12: 512-513.

18. El Hayderi L, Paurobally D, Fassotte MF, et al. (2013) Herpes simplex virus type-I and pyogenic granuloma: a vascular endothelial growth factor-mediated association? Case Rep dermatol 5: 236-243.

19. Yazdanian S, Parish LC, Lambert PC, Lambert WC, et al. (2013) Pyogenic granuloma: an enigma within a paradox or a solution in search of a problem. Skinmed 11: 74-77.

20. Jafarzadeh H, Sanatkhani M, Mohtasham N (2006) Oral pyogenic granuloma: a review. J Oral Sci 48: 165-175.

21. Ximenes M, Triches TC, Cardoso M, Bolan M (2013) Pyogenic granuloma on the tongue: a pediatric case report. Gen Dent 61: 27-29.

22. Yamashita K, Arimura Y, Saito M, lida T, Suzuki T, et al. (2013) Pyogenic granuloma of the small bowel. Endoscopy

23. Bacher J, Assaad D, Adam DN (2011) Pyogenic granuloma of the foot with satellitosis: a role for conservative management. J Cutan Med Surg 15: 58-60.
24. Hayashi M, Suzuki T (2011) Case of subcutaneous lobular capillary hemangioma. J Dermatol 33: 1003-1006.

25. Lee N, Isenstein A, Zedek D, Morrel DS (2013) A case of subcutaneous pyogenic granulomas (lobular capillary hemangioma). Clin Pediatr 51: 88-90.

26. Johnson NA, Haeney J, Yii NW (2011) Intravenous pyogenic granuloma of the finger. J Hand Surg Eur 36: 251-252.

27. Joethy J, Jajeh IA, Tay SC (2011) Intravenous pyogenic granuloma of the hand - a case report. Hand Surg 16: 7-89.

28. Qadir SNR, Manzur A, Raza N (2013) Multiple disseminated pyogenic granulomas. J Coll Physicians Surq Pak 23: 588-589.

29. Zaballoos P, Carulla M, Ozdemir F, Zalaudek I, Banuls J, et al. (2010) Dermoscopy of pyogenic granuloma: a morphological study. $\mathrm{Br} \mathrm{J}$ Dermatol 163: $1229-1237$.

30. Al-Thunayan A, Al-Rehaili M, Al-Meshai O, Al-Qattan MM (2013) Bacillary angiomatosis presenting as a pyogenic granuloma of the hand in an otherwise apparently healthy patient. Ann Plast Surg 70: 652-653.

31. Nthumba PM (2008) Giant pyogenic granuloma of the thigh: a case report. J Med Case Reports 2:95.

32. Gomes SR, Shakir QJ, Thaker P, Tavadia KJ (2013) Pyogenic granuloma of the gingiva: a misomer? - A case report and review of literature. J Indian Soc Periodontol 17: 514-519.

33. Musumeci ML, Lacarrubba F, Anfuso R, Li Calzi M, Micali G (2013) Two pediatric cases of pyogenic granuloma treated with imiquimod $5 \%$ cream: combined clinical and dermatoscopic evaluation and review of the literature. G Ital Dermatol Venereol 148: 147-152.

34. Tritton SM, Smith S, Wong LC, Zagarella S, Fisher G (2009) Pyogenic granuloma in ten children treated with topical imiquimod. Pediatr dermatol 26: 269-272.

35. Lee J, Sinno H, Tahiri Y, Gilardino MS (2011) Treatment options for cutaneous pyogenic granulomas: a review. J Plast Reconstructr Aesthet Surg 64: 12161220.

36. Gilmore A, Kelsberg G, Safranek S (2010) What's the best treatment for pyogenic granuloma? J Fam Pract 59: 40-42. 